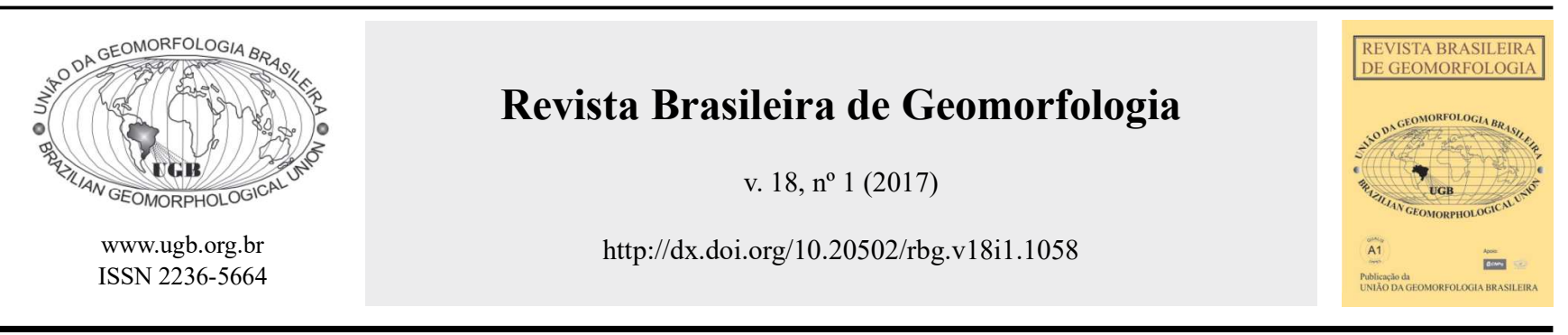

\title{
GÊNESE E EVOLUÇÃO DE TURFEIRAS NAS SUPERFÍCIES GEOMÓRFICAS DA SERRA DO ESPINHAÇO MERIDIONAL - MG
}

\section{GENESIS AND EVOLUTION OF THE PEATLANDS IN GEOMORPHIC SURFACES OF SERRA DO ESPINHAÇO MERIDIONAL - MG}

\author{
Márcio Luiz da Silva \\ Instituto de Geociencias, Universidade Estadual de Campinas \\ Rua João Pandiá Calógeras, 51, Campinas, São Paulo, CEP: 13.083-970, Brasil \\ Email: marcgeo10@yahoo.com.br \\ Alexandre Christófaro Silva \\ Departamento de Ciência Florestal, Universidade Federal dos Vales do Jequitinhonha e Mucuri \\ Rod. MGT 367, km 583, Diamantina, Minas Gerais, CEP: 39.100-000, Brasil \\ Email: alexandre.christo@ufvjm.edu.br
}

\begin{tabular}{l} 
Informações sobre o Artigo \\
\hline Recebido (Received): \\
03/04/2016 \\
Aceito (Accepted): \\
11/02/2017
\end{tabular}

Palavras-chave:

Organossolos; Superfícies

De Aplainamento; Datações

Radiocarbônicas; $\delta 13 \mathrm{c}$;

Paleoambientes.

\section{Keywords:}

Histosols; Planation Surfaces; Radiocarbon Dating; $\delta 13 \mathrm{c}$; Paleoenvironment.

\section{Resumo:}

A Serra do Espinhaço Meridional - SdEM possui litologias predominantemente quartzíticas e é caracterizada por apresentar áreas dissecadas entremeadas a superfícies de aplainamento em diferentes altitudes, onde, nas depressões, ocorrem as turfeiras. Essas superfícies de aplainamentos são resultado de uma sucessão de eventos denudacionais e deposicionais que compartimentou o relevo, ao longo da evolução geodinâmica da Serra. O objetivo desse trabalho foi mapear as turfeiras da porção setentrional da serra e discutir a gênese e evolução desses pedoambientes nas superfícies geomórficas da Serra do Espinhaço Meridional. A determinação da área e mapeamento das turfeiras foi realizada por meio de trabalhos de campo, análises de imagens e de fotografias aéreas. Com o auxílio do vibro-testemunhador coletou-se testemunhos em oito turfeiras. Amostras para datações e caracterização do ciclo fotossintético da cobertura vegetal que colonizou cronologicamente as áreas foram coletadas em diferentes profundidades, para determinação dos isótopos de carbono ( $\delta 13 \mathrm{C}$ e $14 \mathrm{C})$. A porção norte da SdEM ocupa uma área de 1.180.109,00 ha, onde foram mapeados 14.287,55 ha de turfeiras, o que representa $1,2 \%$ da área total. Nas turfeiras predominam os estágios de decomposição avançado (sáprico), seguido do intermediário (hêmico). Quatro níveis de superfícies geomórficas foram identificados em toda a extensão da SdEM: Superfície I (S1), Superfície II (S2), Superfície III (S3) e Superfície IV (S4). Considerando a altimetria como principal fator, a S1 foi cronocorrelacionada com a Superfície Pós-Gondwana e a S2 cronocorrelacionouse com a Superfície Sul-Americana. A Superfície III (S3) teve correspondência 
com a Superfície Sul-Americana I e a Superfície IV (S4), por sua vez, com a Superfície Sul-Americana II. A maioria das turfeiras, desenvolvidas no Quaternário, entre o Pleistoceno e Holoceno, se formaram sobre a Superfície PósGondwana (S1) e na Superfície Sul-Americana (S2), em níveis altimétricos que variam entre 1.100 a 1.400 m. O predomínio de plantas com ciclos fotossintéticos CAM e C3 demonstraram a colonização da SdEM por espécies como bromélia, cactos e algumas euphorbiaceae, típicos de campo rupestre e por árvores e arbustos, ao longo da transição Pleistoceno-Holoceno, reflexos de mudanças ambientais locais e regionais ocorridas no Quaternário, possivelmente associadas a paleoclimas.

\begin{abstract}
:
The Serra do Espinhaço - SdEM has predominantly quartzite lithologies and is characterized by differ altitudes and dissected areas intermingled the planning surfaces, where, in the depressions occur peatlands. These planation surfaces are the result of a succession of denudation and depositional events compartmentalized relief along the geodynamic evolution of the ridge. The aim of this study was to map the peatlands of the northern part of the ridge and discuss the genesis and evolution of pedoenvironments the geomorphic surfaces of the SdEM. The determination of the area and mapping of peatland was conducted through field work, images and aerial photographs analysis. Sampling was carried out in eight peatlands in the northern portion of SdEM. Samples for dating and characterization of the photosynthetic cycle were collected with the help of vibracoring at different depths, depending on local attributes, for determining the carbon isotope ( $\delta 13 \mathrm{C}$ and $14 \mathrm{C})$. The northern portion of SdEM occupies an area of 1,180,109.00 ha, which were mapped $14,287.55$ ha of peatlands, which represents $1.2 \%$ of the total area. In peatlands dominated the stages of advanced decomposition (sapric), followed by intermediate (hemic). Four levels of geomorphical surfaces were identified throughout the length of SdEM: Surface I (S1), Surface II (S2), Surface III (S3) and Surface IV (S4). Considering the altimetry as the main factor, the S1 was cronocorrelated with Post-Gondwana Surface and S2 cronocorrelated with the South American Surface. The Surface III (S3) had correspondence with the South American Surface I and Surface IV (S4), in turn, with the South American Surface II. Most peatlands developed in Quaternary between the Pleistocene and Holocene, formed on Post-Gondwana Surface (S1) and in the South American Surface (S2) in altimetric levels ranging between 1,100-1,400 meters. The predominance of plants with photosynthetic cycles CAM and C3 showed colonization of SdEM by species such as bromeliads, cacti and some euphorbiaceae typical of rupestrian fields and trees and shrubs along the PleistoceneHolocene transition, reflections of local and regional environmental changes occurred in the Quaternary, possibly associated with paleoclimates.
\end{abstract}

\section{Introdução}

O Espinhaço corresponde a um conjunto de elevações alinhadas na direção norte-sul, desde os limites dos Estados do Piauí-Bahia-Pernambuco ao norte, até a região central do Estado de Minas Gerais (ALMEIDA-ABREU, 1989). A sua parte meridional estende-se por cerca de $300 \mathrm{~km}$, desde o Quadrilátero Ferrífero (19,5 $5^{\circ}$ $\mathrm{S})$ até a região de Olhos d'Água $\left(17^{\circ} \mathrm{S}\right)$. Para Saadi (1995) o termo planalto define de maneira mais clara a realidade fisiográfica desse conjunto de terras altas de Minas Gerais. A Serra do Espinhaço Meridional (SdEM) abrange cerca de 3,5 milhões de ha, onde vivem cerca de 700 mil pessoas, em 53 municípios (SILVA, 2005). Por possuir beleza cênica impressionante, biodiversidade endêmica e sistemas naturais raros, peculiares e intimamente relacionados ao endemismo, como as turfeiras, foi classificada pela UNESCO como "Reserva da Biosfera Terrestre".

Quanto à evolução geodinâmica do Espinhaço, uma sucessão de eventos denudacionais e deposicionais compartimentou o relevo da serra e formou 5 níveis de aplainamento entre 1000 e $1800 \mathrm{~m}$ de altitude (SAADI e VALADÃO, 1987), correlacionados respectivamente com as Superfícies de Aplainamento Gondwana e Pós-Gondwana, Sul Americana, Paraguaçu e Velhas, propostas por King (1956). Nesses níveis de aplainamento são encontradas as turfeiras, formadas pelo acúmulo em sucessão de restos vegetais, em locais que apresentam condições que inibem a atividade de microrganismos decompositores, como excesso de umidade, baixo $\mathrm{pH}$, escassez de oxigênio e nutrientes e temperaturas 
amenas (PONTEVEDRA-POMBAL e MARTINEZ-CORTIZAS, 2004; SILVA et al., 2013a, 2013b), onde a matéria orgânica é humificada e muito lentamente mineralizada. A matéria vegetal vai perdendo gradativamente a estrutura primária, originando produtos residuais que reagem novamente e se polimerizam (processos biogeoquímicos), formando compostos de estruturas complexas, com o enriquecimento contínuo de carbono fixo (PEREIRA et al., 2005).

No Espinhaço Meridional, as turfeiras que se situam em posições altimétricas de 1.000 a $1.200 \mathrm{~m}$ e acima de 1.700 m são mais recentes (Holocênicas), ao passo que aquelas que ocupam posições entre 1.200 e 1.700 $\mathrm{m}$ de altitude são mais antigas, datando do Pleistoceno Superior (SILVA e SILVA, 2016).

Estima-se para todo o planeta cerca de 420 milhões de ha de turfeiras, o equivalente a $4,2 \%$ da superfície da Terra (GORHAM, 1991). A maior parte, cerca de 350 milhões de ha, ocorre no Hemisfério Norte e, entre 30,5 e 45,9 milhões de ha encontram-se nos Trópicos (RIELEY et al., 2008). Entretanto, o mapa de distribuição dos organossolos no planeta Terra $(\mathrm{FAO}, 1990)$ não identifica estes solos no Território Nacional. Valladares (2003) estimou que no Brasil as turfeiras ocupam cerca de 611.883 ha, o que corresponde a aproximadamente $0,07 \%$ do território nacional. Nesse estudo, porém, não há menção às turfeiras da Serra do Espinhaço Meridional. Nesse sentido, enquanto o mapeamento da FAO (1990) desconsidera a ocorrência de organossolos no Brasil, os estudos de Valladares (2003) negligenciam a existência de turfeiras no Espinhaço Meridional. Uma reversão nessa estatística poderia acarretar maiores pesquisas das turfeiras (organossolos) no Brasil, em seus potenciais usos e aplicações.

As turfeiras são importantes reservatórios de carbono. Martinelli et al. (2009) estimaram que o estoque de carbono nos solos do planeta Terra seja da ordem de 1,6 Pg, distribuídos por cerca de 10 bilhões de ha. Analisando em conjunto os dados de Gorham (1991) e Martinelli et al. (2009), obtém-se que as turfeiras representam 4,2 \% dos solos do Planeta e estocam 28,4 $\%$ de seu carbono.

Além de serem relevantes sumidouros de carbono e reservatórios de água, as turfeiras também se destacam como testemunhos de mudanças paleoambientais (BEHLING, 1995; SHOTYK et al., 1997; PONTEVEDRA-POMBAL e MARTINEZ CORTI-
ZAS, 2004; SILVA et al., 2009a, 2009b; CAMPOS, 2009; CAMPOS et al., 2010, 2011, 2012; HORAK, 2009; HORAK et. al., 2011; SILVA et al., 2013a, 2013b, 2013c; HORAK-TERRA et. al., 2014, 2015), registrando indícios de alterações paleovegetacionais e paleoclimáticas durante o Quaternário. A matéria orgânica do solo proveniente da vegetação que coloniza as turfeiras constitui-se em importante evidência de possíveis variações no clima e na vegetação nos últimos milhares de anos (VICTORIA et al., 1995; GOUVEIA, 1997, 2001; SANAIOTTI et al., 2002; SCHELLEKENS et al., 2014).

Nesse sentido, o objetivo desse trabalho foi mapear as turfeiras da porção norte da serra e discutir a gênese e evolução desses pedoambientes nas superfícies geomórficas da Serra do Espinhaço Meridional.

\section{Caracterização da Área de Estudo e Contexto Ge- ológico}

A região de estudos corresponde a uma área de 1.180.109 ha da porção norte da Serra do Espinhaço Meridional, em Minas Gerais e se situa entre os paralelos $17^{\circ} 40^{\prime}$ e $19^{\circ} 30^{\prime} \mathrm{S}$ e entre os meridianos $42^{\circ}$ e $44^{\circ}$ W (Figura 1).

A Serra do Espinhaço em sua porção meridional bordeja o sudeste do Cráton do São Francisco e estende-se por cerca de $300 \mathrm{~km}$ na direção S-N, desde o Quadrilátero Ferrífero, nas proximidades de Belo Horizonte, até a região de Olhos d'Água ao norte de Diamantina. O clima presente é, de acordo com a classificação de Köppen, Cwb, ou seja, mesotérmico com chuvas de verão e verões brandos. A temperatura média anual é de $18,7^{\circ} \mathrm{C}$, com invernos frios e secos e verões brandos e úmidos e a precipitação média anual é de $1.500 \mathrm{~mm}$ (SILVA et al., 2005).

No Espinhaço Meridional, superfícies de aplainamento escalonadas estão separadas por áreas com alto grau de dissecação, onde o relevo é montanhoso e escarpado e são muito frequentes os afloramentos de rochas metareníticas do Supergrupo Espinhaço. Os solos predominantes são neossolos litólicos distróficos típicos, neossolos quartzarênicos órticos e hidromórficos (SILVA et al., 2005), substratos de tipologias do bioma cerrado, como o campo rupestre e o campo cerrado. Em diversas depressões das superfícies de aplainamento, as cabeceiras de drenagem estão preenchidas por turfeiras, que constituem as nascentes de inúmeros cursos de águas escuras. 


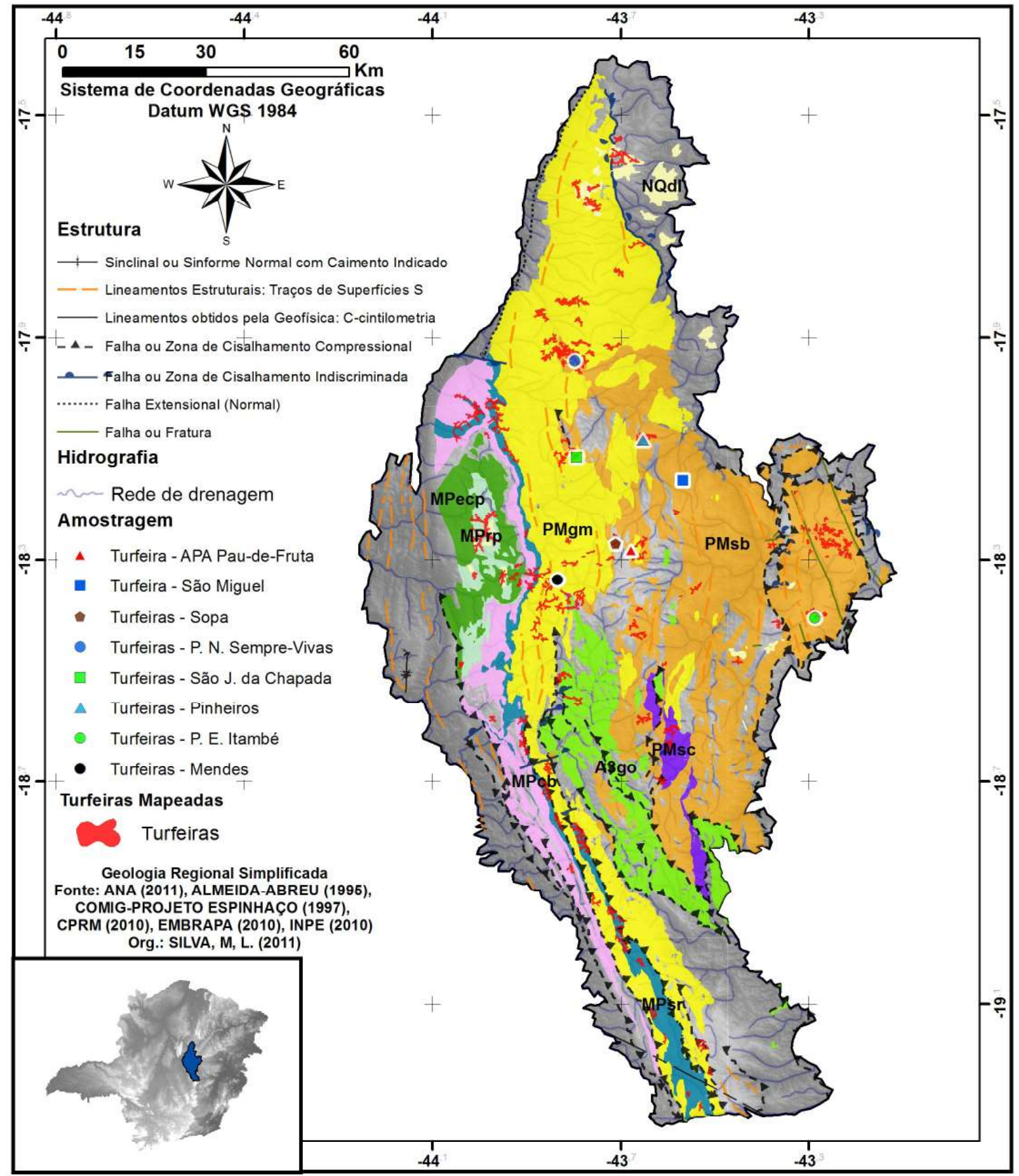

\section{FORMAÇÕES SUPERFICIAIS}

Cenozóico (Terciário-Quaternário)

Cobert. detrito-later. ferrug. - NQdl: laterita, areia, argila e cascalho

\section{SUPERGRUPO ESPINHAÇO}

\section{Grupo Conselheiro Mata - Mesoproterozóico}

Formação Córrego Pereira - MPecp: mica quartzito, quartzito

Formação Rio Pardo Grande - MPrp: filito, metasiltito, quartzito

Formação Santa Rita - MPsr: filito, metasiltito, quartzito

Formação Córrego dos Borges - MPcb: filito, quartzito

\section{SUPERGRUPO ESPINHAÇO}

Grupo Guinda - Paleoproterozóico

Formação Sopa-Brumadinho - PMsb: filito, mica quartzito Formação Galho do Miguel - PMgm: argilito, quatzito Membro da Formação Sopa-Brumadinho

Membro Campo Sampaio - PMsc: arenito, filito, rocha metapelitica

\section{COMPLEXO BASAL}

Mesoarqueano

Complexo Gouveia - A3go: granitóide, gnaisse

Figura 1 - Area ocupada por turfeiras nas principais unidades geológicas da Serra do Espinhaço Meridional - SdEM. 
Essas turfeiras são extremamente ácidas, apresentam baixos teores de nutrientes, CTC muito elevada, densidade em torno de $0,5 \mathrm{~kg} \mathrm{dm}^{-3}$ e permeabilidade muito baixa, permanecendo saturadas com água o ano todo (SILVA et al., 2009a, 2009b).

Na SdEM, as turfeiras mapeadas (SILVA, 2012; SILVA et al., 2013c) ocorrem sobre 9 unidades geológicas: formações Galho do Miguel, Córrego Borges, Santa Rita e Rio Pardo Grande; Membro Campo Sampaio; Complexo Gouveia e Coberturas detrito-lateríticas ferruginosas (Figura 1).

As formações Córrego Borges, Córrego Pereira, Santa Rita e Rio Pardo Grande pertencem ao Grupo Conselheiro Mata, enquanto a Formação Galho do Miguel e Sopa-Brumadinho correspondem ao Grupo Guinda (ALMEIDA-ABREU, 1995). Tanto o Grupo Conselheiro Mata como o Guinda integram o Supergrupo Espinhaço (Figura 1). As Coberturas detrito-lateríticas ferruginosas correspondem às formações superficiais terciário-quaternárias.

Segundo Almeida-Abreu e Pflug (1994), as estruturas regionais características da SdEM são representadas por falhas de empurrão orientadas no sentido N-S e NNW-SSE. A compressão se deu de E para W e o grau de deformação expresso nas unidades do Supergrupo Espinhaço cresce de W para E. A borda leste é caracterizada por este tipo de estrutura, as quais se encontram na zona proximal da colisão que edificou o orógeno (SAADI, 1995). Observa-se ainda, no orógeno em geral, uma grande quantidade de falhamentos indiscriminados no sentido WNW-ESE, falhas NE-SW frequentemente destrais, transcorrências E-W e falhas de transferência WNW-ESE. A natureza dessas estruturas geológicas se destaca como importantes fatores condicionantes no processo de gênese e evolução das turfeiras nesse ambiente.

\section{Materiais e Métodos}

\section{Levantamentos de Campo}

Os trabalhos de campo foram realizados em turfeiras previamente definidas, segundo critérios altimétricos e pelo contexto geológico. Oito turfeiras (São Miguel, Pinheiro, Mendes, São João da Chapada, Sempre Vivas, Itambé, Sopa e Pau-de-Fruta) foram mapeadas detalhadamente no campo e amostradas para caracterização dos organossolos (EMBRAPA, 2006). Foram divididas em transectos espaçados $100 \mathrm{~m}$ entre si e a cada $20 \mathrm{~m}$, dentro deles, foi aferida a profundidade com o auxílio de uma baliza de ferro e realizado o georreferenciamento do ponto com o auxílio de GPS. O procedimento de amostragem consistiu em introduzir um tubo de PVC ( $230 \mathrm{~cm}$ de comprimento e 50 mm de diâmetro), com a extremidade superior destampada, até o substrato basal da turfeira em pontos representativos. Em seguida o tubo foi vedado, com uma tampa removível inserida em sua extremidade superior, puxado à superfície e colocado na horizontal. Após esse procedimento, a tampa foi retirada e, com uma baliza, foi empurrado lentamente para dentro do tubo um êmbolo de madeira. As amostras, então expulsas do tubo, foram assentadas numa pá reta e condicionadas em sacos plásticos.

A determinação do estágio de decomposição das camadas das turfeiras foi realizada em campo, segundo a escala de decomposição de von Post (STANEK e SILC, 1977), descrita em Embrapa (2006). O método consiste na compressão de uma amostra de turfeira recém coletada na mão e a partir do volume que sai entre os dedos e o volume que permanece na mão, a amostra é classificada em uma escala que vai de não decomposta até completamente decomposta.

Com o auxílio do vibro-testemunhador coletou-se testemunhos em oito turfeiras. Amostras para datações e caracterização do ciclo fotossintético da cobertura vegetal que colonizou cronologicamente as áreas foram coletadas em diferentes profundidades, para determinação dos isótopos de carbono $\left(\delta^{13} \mathrm{C}\right.$ e $\left.{ }^{14} \mathrm{C}\right)$.

\section{Aquisição do Banco de Dados}

Todos os trabalhos cartográficos de mapeamento e caracterização da área de estudo foram elaborados a partir de observações de campo (com auxílio de GPS e cartas topográficas) e com a base de dados da Agência Nacional de Águas (ANA), Empresa Brasileira de Pesquisa Agropecuária (EMBRAPA), Instituto Brasileiro do Meio Ambiente e dos Recursos Naturais Renováveis (IBAMA), Instituto Brasileiro de Geografia e Estatística (IBGE), Instituto Mineiro de Gestão das Águas (IGAM), Instituto Nacional de Pesquisas Espaciais (INPE), GeoMINAS, Ministério do Meio Ambiente (MMA) e Companhia de Pesquisa de Recursos Minerais (CPRM), obtidos em 2009, 2010 e 2011.

Para cobertura de toda a área de estudo foram utilizadas imagens de radar correspondentes às folhas SE23XC (Pirapora), SE23ZA (Curvelo), SE23ZB (Guanhães), SE23ZC (Belo Horizonte), SE23ZD (Ipatinga) e SE23XD (Capelinha), disponibilizadas pela Embrapa (SRTM obtidos pela NASA).

As imagens do satélite Landsat- 5 foram adquiridas da base de dados do INPE, entre 2010 e 2011. A resolução temporal das bandas $3,4,5$ e 7 da órbita 218 e pontos 72 e 73 (que abrange toda a SdEM) compreendeu o período entre 01.01.2009 a 26.11.2010. 


\section{Tratamento e Processamento dos Dados}

Inicialmente foi feito o tratamento das imagens SRTM no ENVI 4.5, pela opção Topographic - Replace Bad Values. Posteriormente os dados SRTM foram importados para o ambiente do aplicativo ArcGIS 9.3, onde todas as imagens foram mosaicadas e se procedeu a distribuição dos pontos de observação e a individualização dos valores digitais das células em intervalos de $50 \mathrm{~m}$, originando uma imagem de cotas hipsométricas com essa mesma equidistância. Os processos de mosaicamento, correção geométrica (georreferenciamento), registro e composição RGB das imagens de satélites foram feitos através do ENVI 4.5 e do ArcGIS 9.3.

\section{Mapeamento das Turfeiras}

As turfeiras foram pré-identificadas e delimitadas com auxílio de fotografias aéreas, imagens do Google Earth, imagens do satélite Landsat-5 e imagens de radar. Os softwares utilizados foram o ENVI 4.5 e o ArcGIS 9.3. A validação da identificação foi realizada nos trabalhos de campo.

O padrão de formação das turfeiras foi interpretado em campo, o qual se repetiu em todos os pontos amostrados (elas se desenvolvem em locais pouco deprimidos a planos, onde a drenagem é interceptada por afloramentos rochosos, sendo os capões de mata uma feição típica desses pedoambientes). As fotografias aéreas, por meio de suas características (padrão, textura, tamanho dos objetos, dentre outros) também serviram como instrumento na identificação das turfeiras.

As imagens de radar contribuíram significativamente para a determinação do padrão das turfeiras, pois permitiram identificar morfologias com feições típicas de ambientes turfosos, além de auxiliar na caracterização e na verificação da distribuição espacial desses pedoambientes nas superfícies da SdEM.

Com a imagem de satélite mosaicada, corrigida e registrada, as turfeiras foram determinadas eliminando todos os outros elementos componentes da paisagem (água, solo exposto, rocha, floresta nativa, floresta plantada), a partir da classificação supervisionada Maxver (Método da Máxima Verossimilhança) do Software ENVI 4.5, com uma acurácia de $93,3 \%$ e estimativa de erro de $6,7 \%$. Após essas etapas sucessivas, a classificação foi refinada com a validação por meio de novos trabalhos de campo. Por fim, foram vetorizadas todas as áreas de turfeiras e efetuados os cálculos de área e volume, com a utilização do Software ArcGIS 9.3 pela opção calculate geometry e do GPS Trackmaker Pro.

\section{Determinações Analíticas}

Treze amostras das Turfeiras Pinheiro, Sempre-Vivas I e III, São Miguel e Pico do Itambé I e II foram coletadas, secas ao ar, moídas em grau de porcelana, passadas em peneiras de crivo $0,053 \mathrm{~mm}$ e enviadas para determinação dos isótopos de carbono $\left(\delta^{13} \mathrm{C}\right.$ e $\left.{ }^{14} \mathrm{C}\right)$ por espectrometria de cintilação líquida de baixa radiação de fundo (PESSENDA e CAMARGO, 1991) no laboratório de ${ }^{14} \mathrm{C}$ do CENA/USP.

\section{Análises Estatísticas}

A estatística descritiva, envolvendo os cálculos e gráficos, foi efetuada utilizando-se o software de Planilha Eletrônica e o ArcGIS 9.3.

\section{Resultados}

Turfeiras do Setor Norte da Serra do Espinhaço Meridional

A porção setentrional da Serra do Espinhaço Meridional (SdEM) ocupa uma área de 1.180.109,00 ha, onde foram mapeados $14.287,55$ ha de turfeiras, o que representa $1,2 \%$ da área total. Essas turfeiras ocupam um volume médio de $170.021 .845,00 \mathrm{~m}^{3}$, armazenam 4.488.576,71 t de matéria orgânica e acumulam em média 314,16 t de matéria orgânica por ha (SILVA et al., 2013c).

Das áreas mapeadas, $24,6 \%$ das turfeiras ocorrem sobre a Formação Galho do Miguel, onde predominam amplamente os quartzitos, e aproximadamente $25 \%$ se desenvolveram nos litotipos da Formação Sopa-Brumadinho, sobre litologias quartizíticas e filíticas (SILVA et al., 2013c). As turfeiras do Grupo Guinda (Figura 1), que correspondem por aproximadamente $50 \%$ desses pedoambientes na SdEM, se desenvolveram em pequenas depressões, onde a drenagem é interceptada por afloramentos rochosos, sendo os capões de mata uma feição típica nesses ambientes (Figura 2). A Formação Santa Rita (com litologias de filitos, metassiltitos e quartzitos) responde por $17,4 \%$ das turfeiras da porção norte da SdEM (SILVA et al., 2013c).

As turfeiras se distribuem pelas superfícies de aplainamento situadas entre 1.000 e $1.200 \mathrm{~m}$, entre 1.200 e $1.400 \mathrm{~m}$, entre 1.400 e $1.650 \mathrm{~m}$ e entre 1.650 e 1.800 $\mathrm{m}$ de altitude (SILVA et al., 2013c).

Essas turfeiras ocorrem nas três grandes bacias da serra do Espinhaço Meridional. Na Bacia do Rio São Francisco, que corresponde a cerca de $44 \%$ da área estudada, se encontram $75,07 \%$ das turfeiras da SdEM, enquanto que na Bacia do Rio Jequitinhonha, que corresponde a cerca de $30 \%$ da área estudada, ocorrem $23,72 \%$. 
$\mathrm{Na}$ Bacia do Rio Doce são encontradas somente 1,21\% das turfeiras do Espinhaço Meridional (SILVA, 2012).

Nas turfeiras da SdEM predominam os estágios de decomposição avançado (sáprico), seguido do intermedi- ário (hêmico). A taxa de crescimento vertical variou entre 0,058 e $0,43 \mathrm{~mm}^{\text {ano }}{ }^{-1}$, enquanto a taxa de acúmulo de carbono oscilou entre 0,95 e $53,91 \mathrm{~g} \mathrm{~m}^{-2}$ ano $^{-1}$ (SILVA, 2012; SILVA et al., 2013c).

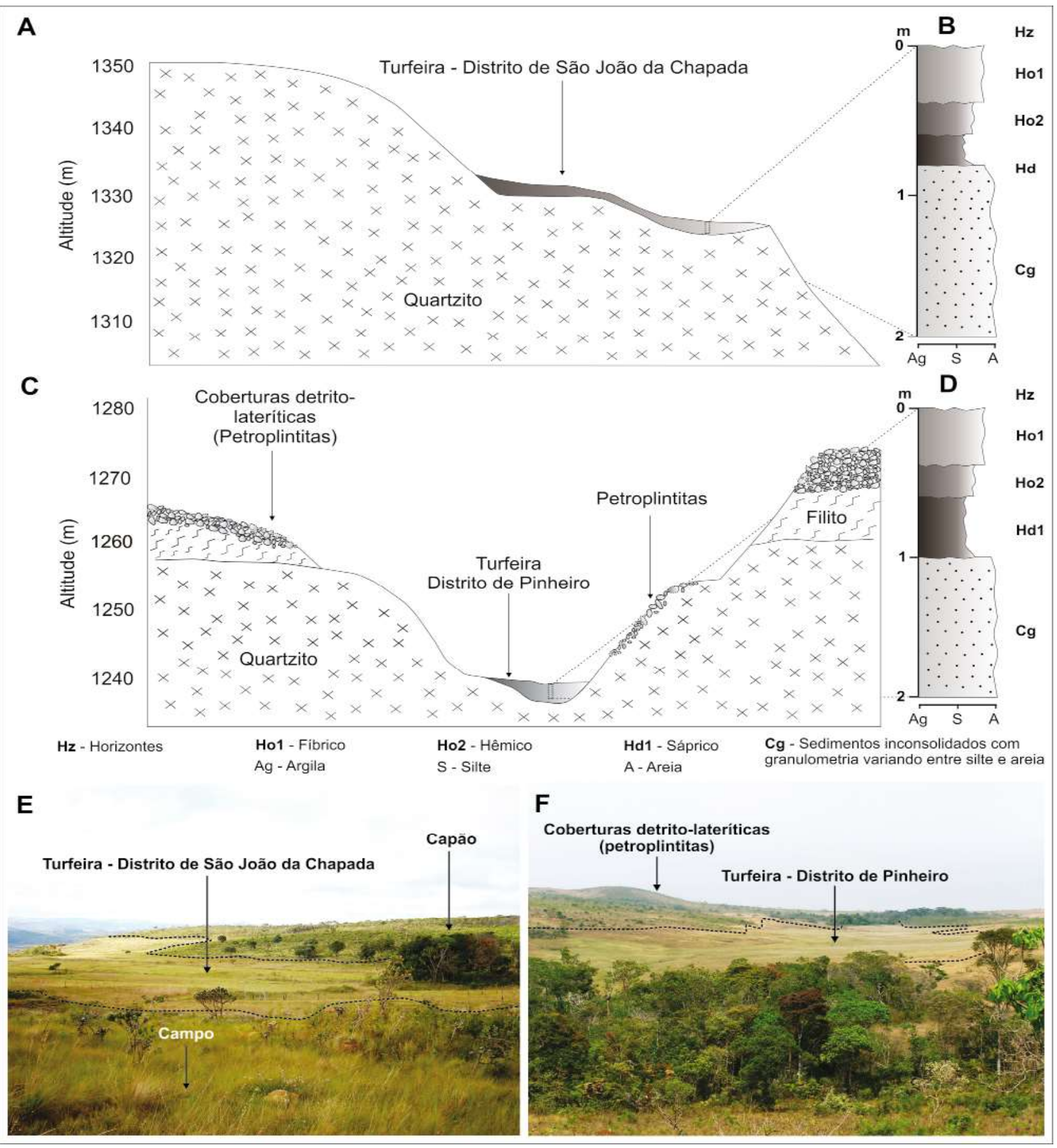

Figura 2 - A) Ambiente de desenvolvimento de turfeiras na Formação Galho do Miguel, Grupo Guinda; B) Seção colunar típica de turfeiras formadas sobre quartzitos; C) Ambiente de desenvolvimento de turfeiras na Formação Sopa-Brumadinho, Grupo Guinda; D) Seção colunar típica de turfeiras desenvolvidas na Formação Sopa-Brumadinho; E) Ambiente de formação de turfeiras no Distrito de São João da Chapada, Municipio de Diamantina - MG; F) Ambiente de formação de turfeiras no Distrito de Pinheiro, Município de Diamantina. Fonte: Adaptado de Silva (2012) e Campos (2014). 
Composição Isotópica $\left(\delta^{13} \mathrm{C}\right)$ e Idades Radiocarbônicas das Turfeiras

De acordo com as datações radiocarbônicas, as turfeiras da SdEM teriam começado a se formar a 42.175 \pm 3.390 anos A.P., no final do Pleistoceno (Tabela 1).

Os valores de $\delta^{13} \mathrm{C}$ variaram de -20,25 a -28,04\%o (Tabela 1), evidenciando mudanças na estrutura e composição da vegetação da SdEM ao longo do Quaternário, embora tenham predominado plantas do ciclos fotossintéticos $\mathrm{C}_{3}$ e CAM.
De acordo com Martinelli et al. (2009), as espécies $\mathrm{C}_{3}$ apresentam valores $\delta^{13} \mathrm{C}$ variando entre -24 e -38 $\%$, espécies $\mathrm{C}_{4}$ apresentam valores entre -11 e $-15 \%$ e espécies CAM apresentam valores entre -11 e -29\%. Para Boutton (1991), espécies CAM apresentam valores para $\delta^{13} \mathrm{C}$ variando entre -10 e $-28 \%$.

As datações radiocarbônicas e os valores de $\delta^{13} \mathrm{C}$ (Tabela 1), analisados em conjunto com o contexto geológico, geomorfológico e altimétrico, permitiram discutir alguns cenários relacionados com a gênese das turfeiras nas superfícies de aplainamentos da SdEM.

Tabela 1: Idades radiocarbônicas e composições isotópicas de perfis de turfeiras da Serra do Espinhaço MeridionalSdEM.

\begin{tabular}{|c|c|c|c|c|c|c|c|c|}
\hline \multirow[t]{2}{*}{ Local dos Perfis } & \multicolumn{2}{|c|}{ Coordenadas } & \multirow{2}{*}{$\begin{array}{l}\text { Altitude } \\
\text { (m) }\end{array}$} & \multirow{2}{*}{$\begin{array}{l}\text { Prof. } \\
\text { (cm) }\end{array}$} & \multirow{2}{*}{$\begin{array}{l}\text { Idade }{ }^{14} \mathrm{C} \\
\text { (anos A.P.) }\end{array}$} & \multirow{2}{*}{$\begin{array}{c}\text { Idade }{ }^{14} \mathrm{C} \text { Calibrada } \\
\text { (A.P./*I.C.) }\end{array}$} & \multirow{2}{*}{$\begin{array}{l}\delta^{13} \mathrm{C} \\
(\%)\end{array}$} & \multirow[t]{2}{*}{ N. Laborat. } \\
\hline & Lat. & Longit. & & & & & & \\
\hline Pinheiro & 641495 & 8002200 & 1.247 & $0-40$ & \multirow{2}{*}{$\begin{array}{c}5.010 \pm 100 \\
18.800+360 \\
-350\end{array}$} & $5.585-5.941$ & $-20,86$ & CEN 1177 \\
\hline Pinheiro & 641495 & 8002200 & 1.247 & $124-164$ & & $21.517-23.369$ & $-23,72$ & CEN 1176 \\
\hline Sempre-Vivas III & 623041 & 8022418 & 1.168 & $3-6$ & Moderna & $* 1.957-1.959$ & $-23,44$ & CEN 1174 \\
\hline Sempre-Vivas III & 623041 & 8022418 & 1.168 & $35-40$ & $890 \pm 100$ & $663-978$ & $-23,65$ & CEN 1175 \\
\hline . Sempre-Vivas I & 627917 & 8019052 & 1.261 & $0-36$ & Moderna & *1.957- 1.958 & $-20,57$ & CEN 1178 \\
\hline Sempre-Vivas I & 627917 & 8019052 & 1.261 & $36-72$ & $5520 \pm 170$ & $5.928-6.667$ & $-20,25$ & CEN 1179 \\
\hline São Miguel & 649691 & 7994039 & 1.250 & $6-14$ & $6.800 \pm 90$ & $7.665 \pm 165$ & $-20,35$ & CEN 1045 \\
\hline São Miguel & 649691 & 7994039 & 1.250 & $78-86$ & \multirow{4}{*}{$\begin{array}{c}23.450 \pm 540 \\
35.100+5.450 \\
\text { ou }-3.220 \\
38.100+2.250 \\
\text { ou }-1.750 \\
930 \pm 75\end{array}$} & $28.150 \pm 1.285$ & $-21,42$ & CEN 1046 \\
\hline São Miguel & 649691 & 7994039 & 1.250 & $128-136$ & & $38.850 \pm 7.835$ & $-24,91$ & CEN 1049 \\
\hline São Miguel & 649691 & 7994039 & 1.250 & $158-170$ & & $42.175 \pm 3.390$ & $-21,45$ & CEN 1050 \\
\hline Itambé I & 675923 & 7965062 & 1.780 & $30-40$ & & $1.120 \pm 135$ & $-28,04$ & CEN 1051 \\
\hline Itambé II & 674530 & 7964905 & 2.000 & $0-6$ & Moderna & *1.957- 1.959 & $-22,86$ & CEN 1052 \\
\hline Itambé II & 674530 & 7964905 & 2.000 & $12-18$ & $3.010 \pm 70$ & $3.185 \pm 185$ & $-21,28$ & CEN 1053 \\
\hline
\end{tabular}

Obs.: $\mathrm{O}$ resultado está corrigido para o fracionamento isotópico natural $\left(-25 \%\right.$ o e apresentado em idade ${ }^{14} \mathrm{C}$ convencional em anos antes do presente (AP) em $1 \sigma(68,3 \%$ de probabilidade). A idade calibrada, em anos antes do presente(AP) ou Idade Calendário (IC) foi obtida por meio do Software Calib601.

\section{Discussão}

\section{Superfícies Geomórficas e Gênese de Turfeiras na SdEM}

Baseado no modelo digital de elevação, no mapa de relevo sombreado e em perfis topográficos e geológi$\cos$ (transectos A-L), quatro níveis de superfícies foram identificados em toda a extensão da SdEM: S1, S2, S3 e S4 (Figuras 3 e 4). No transecto E-F (Figura 4) foram observados remanescentes da Superfície Gondwana (superfície de cimeira) apontada por King (1956).

A superfície de cimeira se encontra num patamar de altitude de aproximadamente $1.500 \mathrm{~m}$ (Figuras $3 \mathrm{e}$ 4). Segundo Saadi (1995) no Planalto de Diamantina, o nível gondwânico subsiste sob forma de alinhamento NW-SE, entre os municípios de Serro e Diamantina, desaparecendo no Planalto Setentrional.

Na SdEM, a Superfície I (S1) se situa entre 1.250 a $1.400 \mathrm{~m}$, enquanto a Superfície II (S2) corresponde às cotas entre 1.000 e $1.200 \mathrm{~m}$ (Figura 5). A Superfície III (S3) se situa nos níveis de 850 a $900 \mathrm{~m}$ e a Superfície IV (S4), entre os níveis de 600 a 750 m (Figura 4).

Assim, considerando a altimetria como principal fator, a Superfície I (S1) foi cronocorrelacionada com a Superfície Pós-Gondwana (Cretáceo Superior - Paleoceno) apontada por King (1956) na Serra do Espinhaço. A Superfície II (S2) cronocorrelacionou-se com a Superfície Sul-Americana (Eoceno-Oligoceno) de King (1956) e a Superfície Sul-Americana (Cretáceo Superior - Mioceno) identificada por Valadão (1998). A Superfície III (S3) teve correspondência com a Superfí- 
Gênese e Evolução de Turfeiras nas Superficies Geomórficas da Serra do Espinhaço Meridional - MG

cie Sul-Americana I (Mioceno-Plioceno) e a Superfície IV (S4), por sua vez, com a Superfície Sul-Americana II (Plioceno-Quaternário), ambas identificadas por Valadão (1998). Não se procurou aqui discutir questões epistemológicas ou de ordem geocronológica abordadas pelos autores (KING, 1956; VALADÃO, 1998), referente ao mapeamento e nomenclatura das superfícies aplainadas.

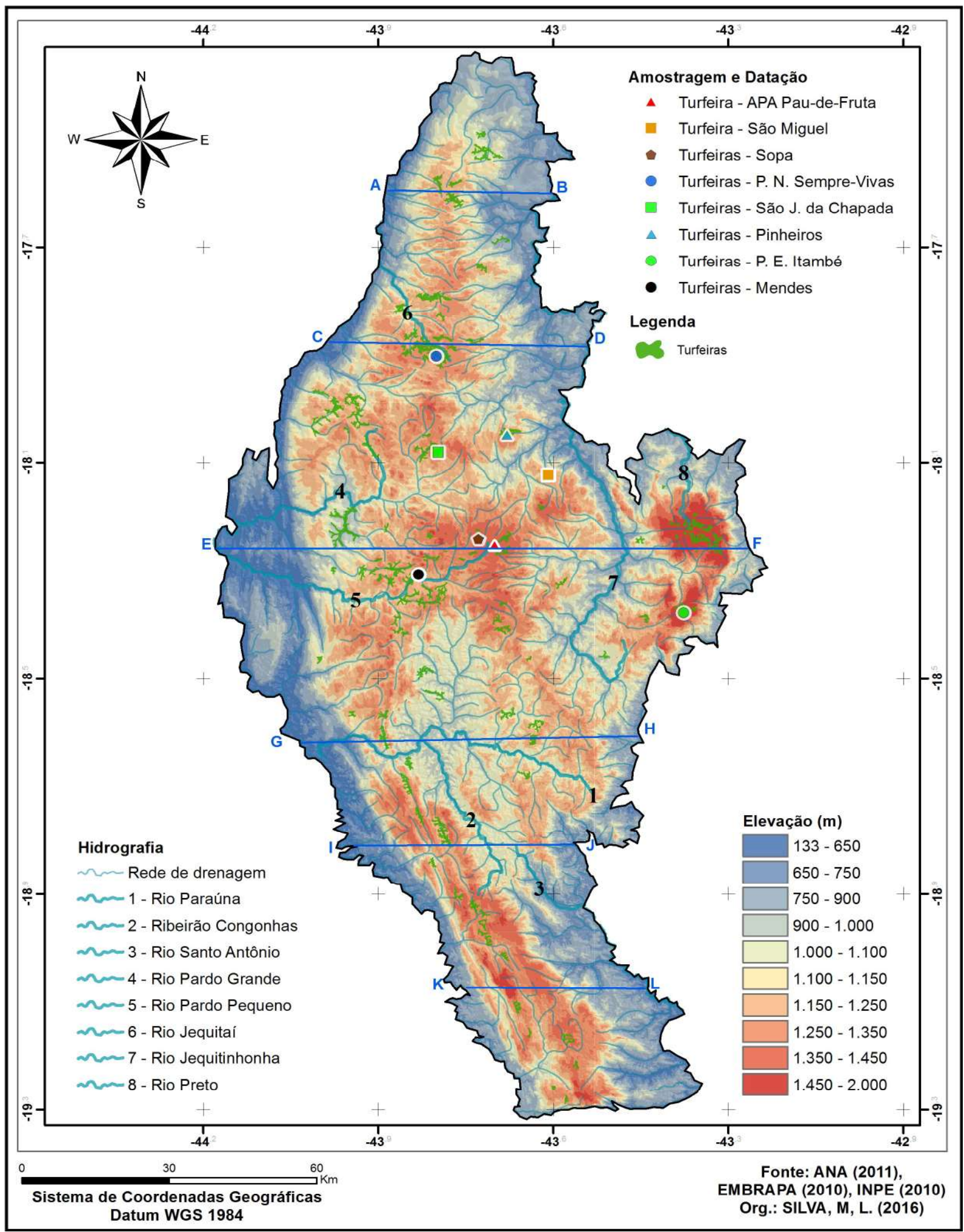

Figura 3 - Mapa hipsométrico e de relevo sombreado com os seis transectos (A-L) e áreas de amostragem na SdEM. 


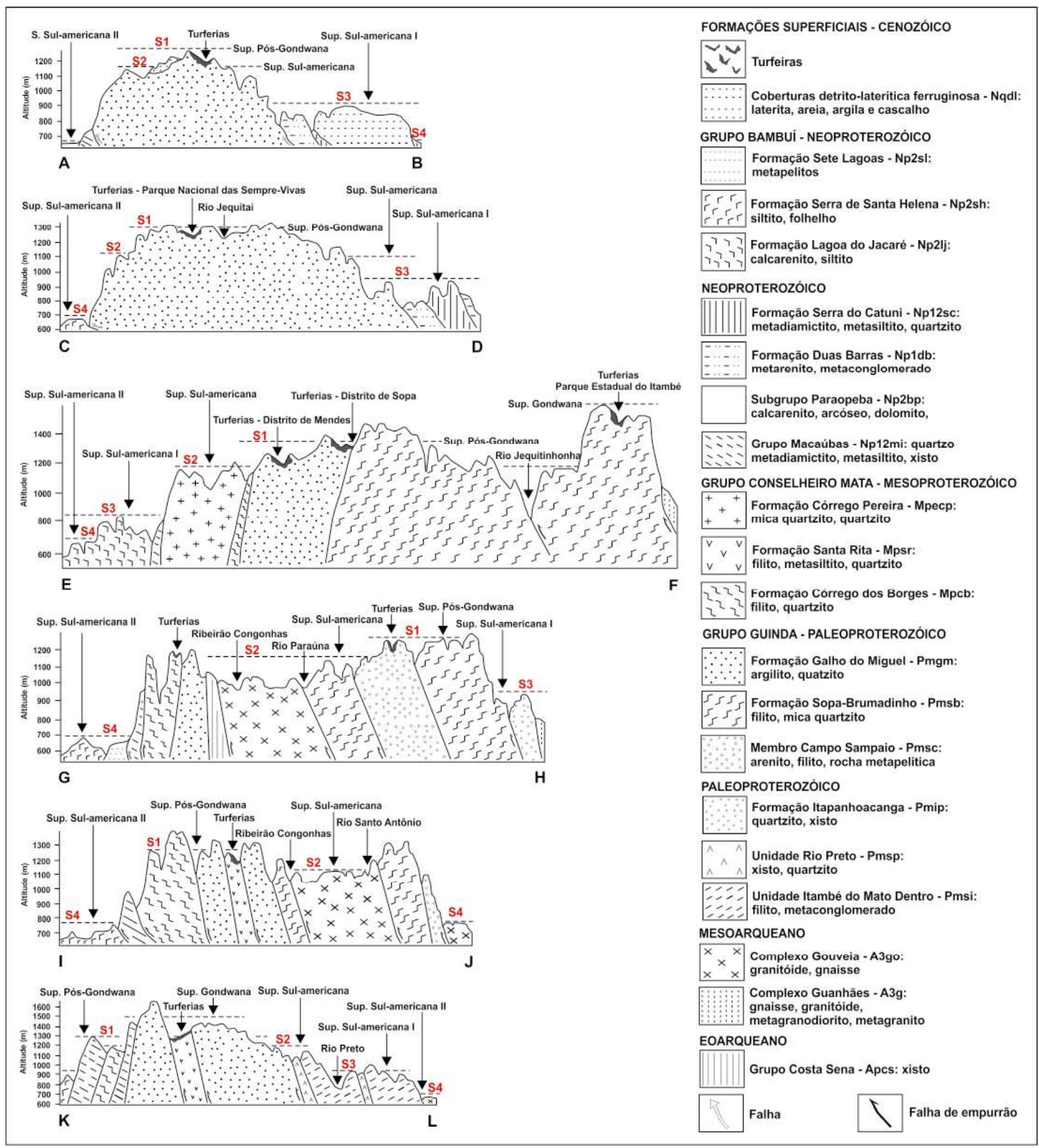

Figura 4 - Transectos do mapa da Figura 3, com a distribuição das turfeiras nos seis perfis topográfico-geológicos na SdEM. A identificação das Superficies de Aplainamento seguiu parcialmente a proposta de King (1956) e a proposta de Valadão (1998).

De acordo com Saadi (1995), na região de Diamantina e Serro, o nível pós-gondwânico seria representado por platô ondulado entre 1.250 e $1.300 \mathrm{~m}$. À oeste de Guinda, restos do mesmo nível a $1.400 \mathrm{~m}$, formando o atual divisor de drenagem São Francisco-Jequitinhonha, testemunhariam a localização do eixo de arqueamento da serra no final do Terciário (SAADI, 1995). Segundo o autor, a Superfície Sul-Americana, por sua vez, mostraria uma inclinação de $\mathrm{W}$ para $\mathrm{E}$, entre $800 \mathrm{~m}$, na região de Serro e mais de $1.000 \mathrm{~m}$, na borda oeste. 
No Planalto de Diamantina, Abreu (1982) definiu três níveis escalonados no relevo regional, correspondentes àqueles propostos por King (1956).

O Nível 3 (Pos-Gondwana), entre 1.200 e 1.400 $\mathrm{m}$, é arqueado ao longo de um eixo meridiano que, sendo localizado entre as nascentes do ribeirão Datas até um pouco ao norte de Guinda (ABREU, 1982). Essa superfície comportaria inselbergs quartzíticos, couraça ferruginosa associada a afloramentos de filitos hematíticos e brejos em depressões hidromórficas de nascentes (dale), onde ocorrem turfeiras sobrepostas a areias e cascalhos fluviais e/ou coluviais e cobertas por solos arenosos (ABREU, 1982; SAADI, 1995).

O Nível 2 (Superfície Sul-Americana), embutido no precedente em altitude de 1.000-1.100 m, ocorre sob forma de retalhos verticalmente desnivelados por falhas normais com direção predominante NW-SE (ABREU, 1982; SAADI, 1995).
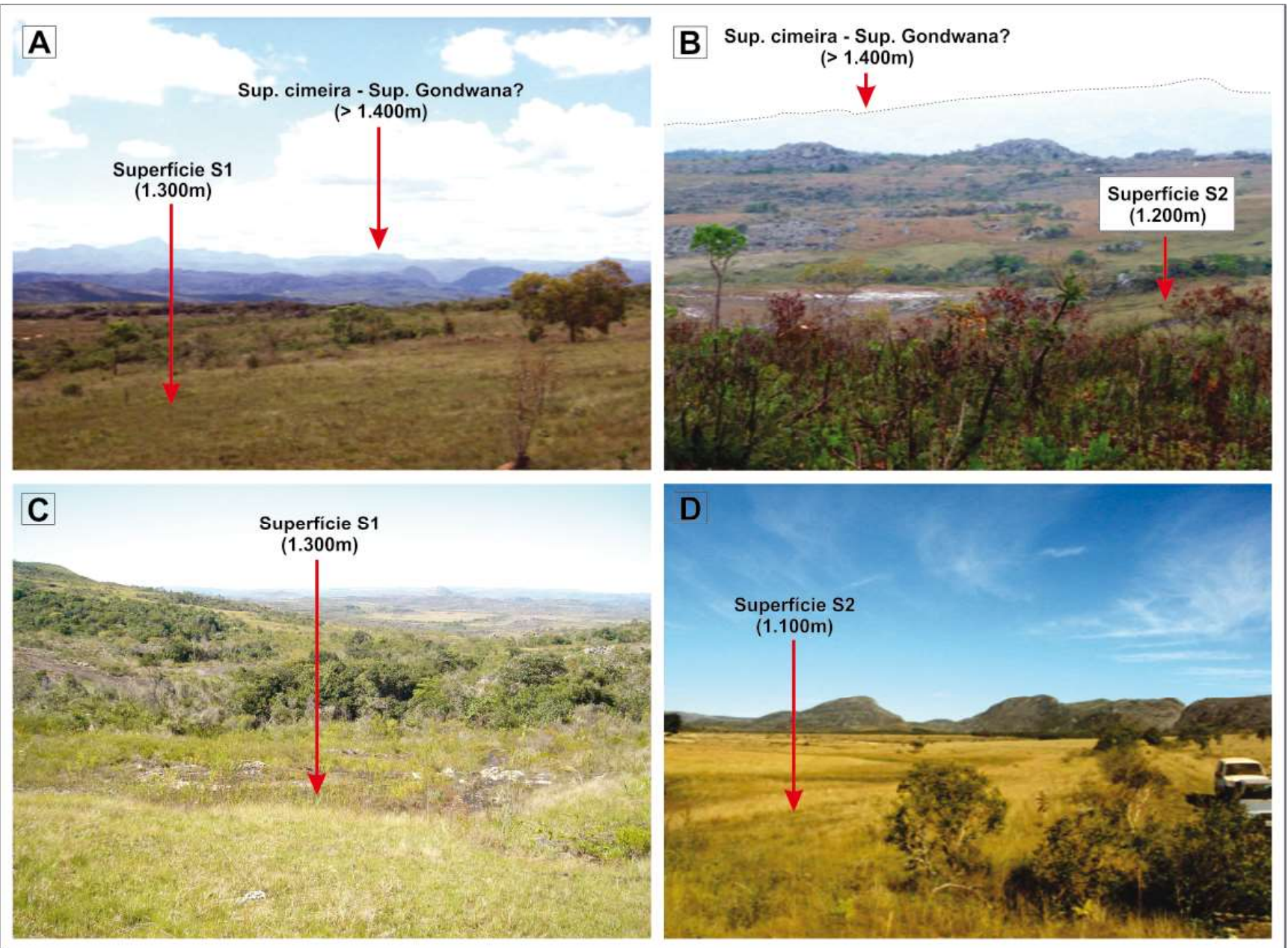

Figura 5 - A) Niveis de superfícies no Municipio de Diamantina: Superfície S1, altimetricamente cronocorrelata com a Superficie PósGondwana e Superficie de cimeira correspondente à Superficie Gondwana identificada por King (1956); B) Niveis de superficies no Distrito de Pinheiro: Superficie de cimeira (Superficie Gondwana) e Superficie S2, altimetricamente cronocorrelacionada com a Superficie Sul-americana proposta por King (1956) e Valadão (1998); C) Superficie S1 correspondente à Superficie Pós-Gondwana (KING, 1956) no Distrito de São João da Chapada; D) Superficie S2 no Distrito de Mendes, altimetricamente cronocorrelacionada com a Superficie Sul-americana proposta por King (1956) e Valadão (1998).

O Nível 1 (Ciclo Velhas) corresponde ao mais alto terraço de cascalho (750-800 m), ao longo do Rio Jequitinhonha e à jusante de Mendanha, representando testemunhos de uma última fase de pedimentação, datada do último período glacial do Hemisfério Norte (ABREU, 1982; SAADI, 1995).

Na Serra do Espinhaço, Valadão (1998) identificou a Superfície Sul-Americana em altitudes médias de 
$1.000 \mathrm{~m}$, podendo alcançar cotas superiores aos 1.200 m. Na SdEM, a Superfície Sul-Americana varia entre 1.100 a 1.200 m (VALADÃO, 1998). As Superfícies de Aplainamento Sul-Americana I ocupariam as cotas médias de 700 a $900 \mathrm{~m}$ e a Sul-Americana II, cotas inferiores a $700 \mathrm{~m}$ (VALADÃO, 1998).

A maioria das turfeiras, que se desenvolveram no Quaternário, entre o Pleistoceno e Holoceno (Tabela 1), se formaram sobre a Superfície Pós-Gondwana (S1) identificada por King (1956) e sobre a Superfície Sul-Americana (S2) mapeada por Valadão (1998) (Figura 4). As turfeiras formadas sobre as Superfícies I e II (S1 e S2) ocorrem em cotas altimétricas entre 1.100-1.500 m (Figura 4 e Tabela 2). As turfeiras do Pico do Itambé fogem à regra, ocorrendo nas altimetrias de 1.780 a $2.000 \mathrm{~m}$ sobre a Superfície Gondwana (Figura 4, Tabelas 1 e 2).

Tabela 2: Distribuição das turfeiras nos níveis altimétricos da Serra do Espinhaço Meridional-SdEM

\begin{tabular}{ccc}
\hline Níveis Altimétricos $(\mathbf{m})$ & Área (ha) & $\mathbf{\%}$ \\
\hline$>1.650$ & 172,25 & 1,21 \\
$1.500-1.650$ & $1.026,87$ & 7,19 \\
$1.350-1.500$ & 794,25 & 5,56 \\
$1.100-1.350$ & $10.755,54$ & 75,27 \\
$1.000-1.100$ & $1.538,64$ & 10,77 \\
Total & $\mathbf{1 4 . 2 8 7 , 5 5}$ & $\mathbf{1 0 0}$ \\
\hline
\end{tabular}

Conforme a Tabela 2, aproximadamente $75 \%$ das turfeiras da SdEM se desenvolveram nos níveis que variam entre 1.100-1.350 m, que correspondem às Superfícies S1 e S2, ou seja, a Superfície Pós-Gondwana e Sul-Americana, que teriam sido formadas entre o Cretáceo Superior e o Oligoceno (KING, 1956; VALADÃO, 1998).

As turfeiras que ocupam as cotas altimétricas entre 1.000 a 1.200 e acima de 1.700 m são, em geral, mais recentes (Holoceno) do que aquelas se encontram em posições entre 1.200 a $1.700 \mathrm{~m}$, que têm suas gêneses iniciadas no Pleistoceno Superior, datadas de $42.175 \pm$ 3.390 anos A.P. (Figuras 3 e 4 e Tabela 1).

O predomínio de plantas com ciclos fotossintéticos CAM e $\mathrm{C}_{3}$ (Tabela 1) demonstraram a colonização da SdEM por espécies como bromélias, cactos e algumas euphorbiaceae, típicas de campo rupestre e por árvores e arbustos, ao longo transição Pleistoceno-Holoceno.

Silva et al (2013a, 2013b), analisando a com- posição isotópica de uma turfeira da SdEM, não encontraram, em nenhum estágio da formação desses pedoambientes, o predomínio de espécies de ciclo fotossintético $\mathrm{C}_{4}$. Esses resultados corroboram com os obtidos por Zinck et al. (2011) em estudos realizados em turfeiras na Venezuela, que encontraram valores de $\delta^{13} \mathrm{C}$ entre $-23,4$ e $-27,3 \%$ e idades radiocarbônicas entre 6.435 e 200 anos A.P.

Tanto as turfeiras estudadas por Zinck et al. (2011) na Venezuela como as européias (SALGADO-LABOURIAU, 2007) são do Holoceno e foram afetadas pela última glaciação (Würm-Wisconsin). As turfeiras da SdEM se formaram tanto no Holoceno como no Pleistoceno (Tabela 1).

Analisando-se em conjunto os teores de $\delta^{13} \mathrm{C}$ e as idades radiocarbonicas entre e dentro das turfeiras (Tabela 1) pode-se inferir que aquelas que tiveram sua formação iniciada no Pleistoceno apresentam evidencias de mudanças na composição florística de sua cobertura vegetal e aquelas com gênese iniciada no Holoceno não apresentam estas evidencias, corroborando os resultados obtidos por Campos et al. (2010), Horak et.al. (2011) e Silva et al. (2013a, 2013b).

Os estudos realizados em turfeiras da SdEM (CAMPOS et al., 2010; HORAK, 2009; HORAK et al., 2011; SILVA et al., 2009a; SILVA et al., 20013a; SILVA et al., 2013c; HORAK-TERRA et al., $2014 \mathrm{e}$ 2015; SCHELLEKENS et al., 2014) atestaram que, ao longo da evolução desses pedoambientes no Pleistoceno e Holoceno, eles presenciaram transformações na paisagem do Espinhaço Meridional, testemunhando mudanças no clima e na vegetação local e regional.

\section{Conclusões}

Na porção setentrional da Serra do Espinhaço Meridional (SdEM), que ocupa uma área de 1.180.109,00 ha, foram mapeados $14.287,55$ ha de turfeiras, o que representa $1,2 \%$ da área total. Nas turfeiras da SdEM predominam os estágios de decomposição avançado (sáprico), seguido do intermediário (hêmico).

Quatro níveis de superfícies geomórficas foram identificadas em toda a extensão da SdEM: Superfície I (S1), Superfície II (S2), Superfície III (S3) e Superficie IV (S4). Considerando a altimetria como principal fator, a S1 foi cronocorrelacionada com a Superfície Pós-Gondwana e a S2 cronocorrelacionou-se com a Superfície Sul-Americana. A Superfície III (S3) teve 
correspondência com a Superfície Sul-Americana I e a Superfície IV (S4), por sua vez, com a Superfície Sul-Americana II.

A maioria das turfeiras, desenvolvidas no Quaternário, entre o Pleistoceno e Holoceno, se formaram sobre a Superfície Pós-Gondwana (S1) e na Superfície Sul-Americana (S2), em níveis altimétricos que variam entre 1.100 a $1.400 \mathrm{~m}$.

Turfeiras que ocupam as cotas altimétricas entre 1.000 a 1.200 m e acima de 1.700 m são, em geral, mais recentes (Holoceno) do que aquelas se encontram em posições entre 1.200 a $1.700 \mathrm{~m}$, que têm suas gêneses iniciadas no Pleistoceno Superior (42.175 3390 anos A.P.).

O predomínio de plantas com ciclos fotossintéticos CAM e $\mathrm{C}_{3}$ demonstraram a colonização da SdEM por espécies como bromélias, cactos e algumas euphorbiaceae, típicos de campo rupestre e por árvores e arbustos, ao longo da transição Pleistoceno-Holoceno, reflexos de mudanças ambientais locais e regionais ocorridas no Quaternário, possivelmente associadas a paleoclimas.

\section{Agradecimentos}

Os autores agradecem à FAPEMIG, à UFVJM, à ESALQ-USP e ao IFSULDEMINAS pelo apoio, fundamental na consolidação dessa pesquisa.

\section{Referências Bibliográficas}

ABREU, A. A. 1982. Análise geomorfológica: reflexão e aplicação (Uma contribuição ao conhecimento das formas de relevo do Planalto de Diamantina - MG). 1982. 296 p. Tese de Livre Docência, Departamento de Geografia, Universidade do Estado de São Paulo, São Paulo, 1982.

ALMEIDA-ABREU, P. A. Geologia das quadrículas Onça e Cuiabá (Gouveia-MG) - região mediana central da Serra do Espinhaço Meridional. 1989. Dissertação (Mestrado em Geologia) - Departamento de Geologia, Universidade Federal do Rio de Janeiro, Rio de Janeiro, 1989.

ALMEIDA-ABREU, P. A. O Supergrupo Espinhaço da Serra do Espinhaço Meridional (Minas Gerais): o rifte, a bacia e o orógeno. Geonomos 3 (1), 1-18, 1995.

ALMEIDA-ABREU, P. A.; PFLUG, R. The geodynamic evolution of the southern Serra do Espinhaço, Minas Gerais, Brazil. Zbl. Geol. Paläont. Teil I 1, 21-44, 1994.
BEHLING, H. A high resolution Holoceno pollen record from Lago do Pires, SE Brazil: vegetation, climate and fire history. Journal of Paleolimnology 14, 253-268, 1995.

BOUTTON, T.W. Stable carbon isotopes ratios of natural materials. II. Atmospheric, terrestrial, marine and freswater environmental. In: COLEMAN, D. C.; FRY, B. (Ed.), Carbon isotopes techniques. Academic Press, New York, pp. 155-171, 1991.

CAMPOS, J. R. R. Caracterização, mapeamento, volume de água e estoque de carbono da turfeira da área de proteção ambiental Pau-de-Fruta, Diamantina - MG. 2009. 101 p. Dissertação (Mestrado em Produção Vegetal - Solo e Água) - Universidade Federal dos Vales do Jequitinhonha e Mucuri, Diamantina, 2009.

CAMPOS, J. R. R. Relação entre morfoestratigrafia e hidrologia na formação das turfeiras da Serra do Espinhaço Meridional (MG). 2014. 99 p. Tese (Doutorado em Solos e Nutrição de Plantas) - Universidade de São Paulo, Escola Superior de Agricultura Luiz de Queiroz, Piracicaba, 2014.

CAMPOS, J. R. R.; SILVA, A. C.; FERNANDES, J. S. C.; FERREIRA, M. M.; SILVA, D. V. Water retention in a peatland with organic matter in diferent deomposition stages. Revista Brasileira de Ciência do Solo 35, 1217-1227, 2011.

CAMPOS, J. R. R.; SILVA, A. C.; VASCONCELLOS, L. L.; SILVA, D. V.; ROMÃO, R. V.; SILVA, E. B.; GRAZZIOTTI, P. H. Pedochronoloy and development of peat bog in the environmental protection area Pau-de-Fruta - Diamantina, Brazil. Revista Brasileira de Ciência do Solo 34, 1965-1975, 2010 .

CAMPOS, J. R. R.; SILVA, A. C.; VIDAL-TORRADO, P. Mapping, organic matter mass and water volume of a peatland in Serra do Espinhaço Meridional. Revista Brasileira de Ciência do Solo 36, 723-732, 2012.

EMBRAPA - Empresa Brasileira de Pesquisa Agropecuária. Centro Nacional de Pesquisa de Solos. Sistema Brasileiro de Classificação de Solos. Brasília: Embrapa Produção de Informação; Rio de Janeiro: Embrapa Solos, 2006.

FAO - UNESCO. Soil Map of the World at scale 1:5.000.000. In: WORD CONGRESS OF SOIL SCIENCE, 14., Kyoto, 1990. Proceedings. Kyoto, International Soil Science Society, 1990.

GORHAM, E. Northern peatlands: role in the carbon cycle and probable responses to climatic warming. Ecological Applications 1 (2), 182-195, 1991.

GOUVEIA, S. E. M. Dinâmica de vegetações durante o 
quaternário recente no sul do amazonas, indicadas pelos isótopos de carbono $\left({ }^{12} \mathrm{C},{ }^{13} \mathrm{C},{ }^{14} \mathrm{C}\right)$ do solo. Geochimica Brasiliensis 11 (3), 355-367, 1997.

GOUVEIA, S. E. M. Isótopos do carbono na avaliação do remonte biológico de Latossolos e Podzólicos e de eventos peleoclimáticos em distintas localidades do Brasil. 2001. 116 p. Tese de Doutorado, Centro de Energia Nuclear na Agricultura, Universidade de São Paulo, São Paulo, 2001.

HORAK, I. Relações pedológicas, isotópicas e palinológicas na reconstrução paleoambiental da turfeira da Área de Proteção Especial (APE) Pau-de-Fruta, Serra do Espinhaço Meridional-MG. 2009. 281 p. Dissertação (Mestrado em Solos e Nutrição de Plantas) - Escola Superior de Agricultura "Luiz de Queiroz" (ESALQ), Universidade de São Paulo, Piracicaba, 2009.

HORAK, I.; VIDAL-TORRADO, P.; SILVA, A. C.; PESSENDA, L. C. R. Pedological and isotopic relations of a highland tropical peatland, Mountain Range of the Southern Espinhaço (Brazil). Revista Brasileira de Ciência do Solo 35, 41-52, 2011.

HORAK-TERRA, I.; MARTÍNEZ-CORTIZAS, A.; DE CAMARGO, P. B.; SILVA, A. C.; VIDAL-TORRADO, P . Characterization of properties and main processes related to the genesis and evolution of tropical mountain mires from Serra do Espinhaço Meridional, Minas Gerais, Brazil. Geoderma 232234, 183-197, 2014.

HORAK-TERRA, I.; MARTÍNEZ-CORTIZAS, A.; LUZ, C.F.P; RIVAS-LÓPEZ, P.; SILVA, A.C.; VIDAL-TORRADO, P. Holocene climate change in central-eastern Brazil reconstructed using pollen and geochemical records of Pau de Fruta mire (Serra do Espinhaço Meridional, Minas Gerais). Palaeogeography, Palaeoclimatology, Palaeoecology 437, 117-131, 2015.

KING, L. C. A geomorfologia do Brasil Oriental. Revista Brasileira de Geografia 18 (2), 3-121, 1956.

MARTINELLI, L. A.; OMETTO, J. P. H. B.; FERRAZ, E. S.; VICTORIA, R. L.; CAMARGO, P. B.; MOREIRA, M. Z. Desvendando questões ambientais com isótopos estáveis. São Paulo: Oficina de Textos, 2009.

PEREIRA, M. G.; ANJOS, L. H. C.; VALLADARES, G. S. Organossolos: ocorrência, gênese, classificação, alterações pelo uso agrícola e manejo. In: TORRADO, P. V.; ALLEONI, L. R. F.; COOPER, M.; SILVA, A. P.; CARDOSO, E. J. (Ed.), Tópicos em Ciência do Solo IV. Sociedade Brasileira de Ciência do Solo, Viçosa, pp. 233-277, 2005.

PESSENDA, L. C. R.; CAMARGO, P. B. Datações radiocarbônicas de amostras de interesse arqueológico e geológico por espectrometria de cintilação líquida de baixa radiação de fundo. Química Nova 14 (2), 98-103, 1991.

PONTEVEDRA-POMBAL, X.; MARTINEZ-CORTIZAS, A. Tuberas de Galicia: processos formativos, distribuición y valor medioambiental. El caso particular de lãs "Serras Septentrionais". Chioglossa 2, 103-121, 2004.

RIELEY, R. A. J. ; WÜST, R. A. J. ; JAUHIAINEN, J. ; STAHLHUT, M. Tropical Peatlands: carbon stores, carbon gas emissions and contribution to climate change processes. In: STRACK, M., Peatlands and Climate Change. Peat Society, Calgary, pp. 44-70, 2008.

SAADI, A. A geomorfologia da Serra do Espinhaço em Minas Gerais e de suas margens. Geonomos 3 (1), 41-75, 1995.

SAADI, A.; VALADÃO, R. C. Evolução geomorfológica quaternária da região de Gouveia, Serra do Espinhaço. In: SIMP. GEOL. MG, 4, Belo Horizonte - MG, 1987. Anais..., SBG/MG, 1987. Bol. SBG/MG, v.7, p. 443-448, 1987.

SALGADO-LABOURIAU, M. L. Critérios e técnicas para o Quaternário. São Paulo: Edgard Blücher, 2007.

SANAIOTTI, T. M.; MARTINELLI, L. A.; VICTORIA, R. L.; TRUMBORE, S. E.; CAMARGO, P. B. Past vegetation changes in amazon savannas by using carbon isotopes of soil organic matter. Biotropica 34, 2-16, 2002.

SCHELLEKENS, J.; HORÁK-TERRA, I.; BUURMAN, P.; VIDAL-TORRADO, P.; SILVA, A. C. Holocene vegetation and fire dynamics in central-eastern Brazil: Molecular records from the Pau de Fruta peatland. Organic Geochemistry 77, 32-42, 2014.

SHOTYK, W; NORTON, S. A.; FARMER, J. G. Summary on peat bog archives of atmospheric metal deposition. Water, air and soil pollution 100 (3), 213-219, 1997.

SILVA, A. C.; HORAK, I.; MARTINEZ-CORTIZAS, A.; VIDAL-TORRADO, P.; RODRIGUES-RACEDO, J.; GRAZZIOTTI, P. H.; SILVA, E. B.; FERREIRA, C. A. Turfeiras da Serra do Espinhaço Meridional - MG: I - caracterização e classificação. Revista Brasileira de Ciência do Solo 33, 1385 1398, 2009a.

SILVA, A. C.; HORAK, I.; VIDAL-TORRADO, P.; MARTINEZCORTIZAS, A.; RODRIGUES-RACEDO, J.; CAMPOS, J. R. R. Turfeiras da Serra do Espinhaço Meridional-MG: II - Influência da drenagem na composição elementar e substâncias húmicas. Revista Brasileira de Ciência do Solo 33, 1399-1408, 2009 b.

SILVA, A. C.; PEDREIRA, L. C. V. S. F.; ALMEIDA ABREU, P. A. (Ed.). Serra do Espinhaço Meridional: paisagens e 
ambientes. Belo Horizonte: O Lutador, 2005.

SILVA, A. C. Solos. In: SILVA, A. C.; PEDREIRA, L. C. V. S. F.; ALMEIDA-ABREU, P. A. (Ed.), Serra do Espinhaço Meridional: paisagens e ambientes. O Lutador, Belo Horizonte, pp. 50-78, 2005.

SILVA, M. L.; SILVA, A. C. Gênese de turfeiras e mudanças ambientais quaternárias na Serra do Espinhaço Meridional-MG. Geociências 35 (3), 393-404, 2016.

SILVA, E. V.; SILVA, A. C.; PEREIRA, R. C.; CAMARGO, P. B.; SILVA, B. P. C.; BARRAL, U. M.; MENDONÇA-FILHO, C. V. Composição lignocelulósica e isotópica da vegetação e da matéria orgânica do solo de uma turfeira tropical: I - composição florística, fitomassa e acúmulo de carbono. Revista Brasileira de Ciência do Solo 37 (1), 121-133, 2013a.

SILVA, E. V.; SILVA, A. C.; SILVA, B. P. C.; CAMARGO, P. B.; PEREIRA, R. C.; BARRAL, U. M.; BOTELHO, A. M. M.; VIDAL-TORRADO, P. Composição lignocelulósica e isótopica da vegetação e da matéria orgânica do solo de uma turfeira tropical: II - substâncias húmicas e processos de humificação. Revista Brasileira de Ciência do Solo 37 (1), 134-144, 2013 b.

SILVA, M. L.; SILVA, A. C.; SILVA, B. P. C.; BARRAL, U. M. SOARES, P. G. S.; VIDAL- TORRADO, P. Surface mapping, organic matter and water stocks in peatlands of the Serra do Espinhaço Meridional - Brasil. Revista Brasileira de Ciência do Solo 37 (5), 1149-1157, 2013c.

SILVA, M. L. Turfeiras da Serra do Espinhaço Meridional: mapeamento e estoque de matéria orgânica. 2012. 139 p. Dissertação (Mestrado em Ciência Florestal) - Universidade Federal dos Vales do Jequitinhonha e Mucuri, Diamantina, 2012.

STANEK, W.; SILC, T. Comparisons of four methods for determination of degree of peat humification (decomposition) with emphasis on the von Post method. Canad. J. Soil Sci. 57, 109-117, 1977.

VALADÃO, R. C. Evolução de longo-termo do relevo do Brasil Oriental: desnudação, superfície de aplanamento e movimentos crustais. 1998. 243 p. Tese (Doutorado em Geologia Sedimentar) - Instituto de Geociências, Universidade Federal da Bahia, Salvador, 1998.

VALLADARES, G. S. Caracterização de organossolos, auxílio à sua classificação. 2003. 142 p. Tese (Doutorado em Ciência do Solo) - Universidade Federal Rural do Rio de Janeiro, Seropédica, 2003.

VICTORIA, R. L.; FERNANDES, F.; MARTINELLI, L. A.; PICCOLO, M. C.; CAMARGO, P. B.; TRUMBORE, S. Past vegetation changes in the Brazilian Pantanal arboreal-grass Savanna ecotone by using carbon isotopes in the soil organic matter. Global Change Biology 1, 101-108, 1995.

ZINCK, J. A.; GARCÍA, P.; PLICHT, J. V. D. Tepui Peatlands: age record and environmental changes. In: ZINCK, J. A.; HUBER, O. (Eds.), Peatlands of the Western Guayana Highlands, Venezuela: properties and paleogeographic significance of peats. Springer, New York, pp. 189-236, 2011 (Ecological Studies v. 217). 